\title{
SPATIAL ASSOCIATION TO CHARACTERIZE THE CLIMATE TELECONNECTION PATTERNS IN ECUADOR BASED ON SATELLITE PRECIPITATION ESTIMATES
}

\author{
Daniela Ballari ${ }^{1}$ *, Lenin Campozano ${ }^{2}$, Esteban Samaniego ${ }^{3}$, Daniel Orellana ${ }^{4}$ \\ ${ }^{1}$ IERSE, Facultad de Ciencia y Tecnología, Universidad del Azuay, Cuenca, Ecuador - dballari@uazuay.edu.ec \\ ${ }^{2}$ Departamento de Ingeniería Civil y Ambiental, Escuela Politécnica Nacional, Quito, Ecuador - lenin.campozano@epn.edu.ec \\ ${ }^{3}$ Departamento de Recursos Hídricos y Ciencias Ambientales, Facultad de Ingeniería, Universidad de Cuenca, Cuenca, Ecuador- \\ esteban.samaniego@ucuenca.edu.ec \\ ${ }^{4}$ LlactaLAB - Ciudades Sustentables, Departamento Interdisciplinario de Espacio y Población, Facultad de Ciencias Agropecuarias, \\ Universidad de Cuenca, Cuenca, Ecuador - daniel.orellana@ucuenca.edu.ec
}

KEY WORDS: Spatial Association, Spatial Patterns, Climate Teleconnections, Satellite Precipitation, Moran's I and LISA Indicators

\begin{abstract}
:
Climate teleconnections show remote and large-scale relationships between distant points on Earth. Their relations to precipitation are important to monitor and anticipate the anomalies that they can produce in the local climate, such as flood and drought events impacting agriculture, health, and hydropower generation. Climate teleconnections in relation to precipitation have been widely studied. Nevertheless, the spatial association of the teleconnection patterns (i.e. the spatial delineation of regions with teleconnections) has been unattended. Such spatial association allows to characterize how stable (heterogeneity/dependent and statistically significant) is the underlying spatial phenomena for a given pattern. Thus our objective was to characterize the spatial association of climate teleconnection patterns related to precipitation using an exploratory spatial data analysis approach. Global and local indicators of spatial association (Moran's I and LISA) were used to detect spatial patterns of teleconnections based on TRMM satellite images and climate indices. Moran's I depicted high positive spatial association for different climate indices, and LISA depicted two types of teleconnections patterns. The homogenous patterns were localized in the Coast and Amazonian regions, meanwhile the disperse patterns had a major presence in the Highlands. The results also showed some areas that, although with moderate to high teleconnection influences, had a random spatial patterns (i.e. non-significant spatial association). Other areas showed both teleconnections and significant spatial association, but with dispersed patterns. This pointed out the need to explore the local underlying features (topography, orientation, wind and micro-climates) that restrict (non-significant spatial association) or reaffirm (disperse patterns) the teleconnection patterns.
\end{abstract}

\section{INTRODUCTION}

Climate teleconnections show remote and large-scale relationships between distant points on Earth, that produce anomalies and variability in the surface climate and precipitation of a region (Carleton, 2003; Z. Liu \& Alexander, 2007). Their influences on local climate are highly variable across large geographic areas (Kiem \& Franks, 2001). Therefore, certain teleconnections can only be detected in certain regions or in certain periods of time. One of the most studied climate teleconnections has been ENSO - El Niño South Oscillation (Diaz, Hoerling, \& Eischeid, 2001), which arises from the atmosphere-ocean interaction in the tropical Pacific and it is measured with several indices, such as the sea surface temperature (SST) in the regions Niño 1+2, 3, 4 and 3.4, as well as indices derived for pressure gradients in the Pacific (SOI) and multivariate indices (MEI).

In Ecuador, the warm phase of ENSO named "El Niño" mainly affects the coastal region of the country with intense precipitations and floods causing infrastructure damage, economic losses and increased incidence of diseases. Thus, it is important to identify climate teleconnections that influence a certain region in order to monitor and anticipate the anomalies that they can produce in the local climate. For instance, in the case of precipitation, these anomalies are related to flood and drought events impacting agriculture, health, risk management and hydropower generation.

Climate teleconnections in relation to precipitation have been widely studied since the beginning of the 20th century, e.g. (Ångström, 1935). In Ecuador, nevertheless, the most studied teleconnection has been ENSO, through the SST on Niño1+2 region (Bendix \& Bendix, 2006; Bendix et al., 2011; MoránTejeda et al., 2015; Pineda et al., 2013; Vuille, Bradley, \& Keimig, 2000). However, beyond the Niño1+2 region, other types of teleconnections have been poorly studied. In addition to the lack of systematic exploration of the different climate teleconnections in Ecuador, there is also the limitation that mainly the Coast region of the country was approached. Less studies had focused on the Highland (Andes) and Amazonian regions.

From a methodological perspective, it is usual to apply correlation methods in order to show the degree of association among precipitation and climate indices (Fierro, 2014; Liu, Chen, \& DaMassa, 2018). Nevertheless, the spatial association of these bivariate correlations has been less studied. Spatial association is related to two key spatial characteristics: heterogeneity and dependence (de Smith, Goodchild, \& Longley, 2018). Spatial heterogeneity refers to the global variation of a phenomenon over the whole study area, and how it is expected to vary across locations. In contrast, spatial dependence refers to

\footnotetext{
* Corresponding author
} 
the persistence of a phenomenon at the local level despite the global variation, and it is related to the fact that an observation in one location is also similar to other observations in the nearby locations. Such similarity will decay with the increase of the distance (Orellana \& Wachowicz, 2011). The spatial association is measured by mean of indicators of spatial autocorrelation (Bivand \& Wong, 2018). By integrating the concept of spatial association in the characterization of climate teleconnection patterns, i.e. its spatial delineation, it is possible to address the following issues: How strong is the spatial association of teleconnections in a given region? How homogeneous or disperse are the teleconnection spatial patterns? Where teleconnections might be interacting with local climate drivers?

Teleconnection studies have focused on studying the correlation at discrete locations, this is at points where rain gauges are deployed, which in turn produce only a partial and discrete knowledge of the teleconnection pattern. In this context, precipitation products with exhaustive spatial continuity such as those obtained from satellites, become an essential source for precipitation estimations. There is a wide diversity of satellite precipitation products (Maggioni, Meyers, \& Robinson, 2016; Salio et al., 2015); among them, the Tropical Rainfall Measurement Mission (TRMM) is one of the most used products because it offers historical records since 1998 (Huffman et al., 2007). For the particular case of Ecuador, TRMM showed an adequate representation of the seasonality of precipitation (Ballari, Castro, \& Campozano, 2016; Ochoa et al., 2014), although with some limitations to represent precipitation along the eastern escarpments of the Andes. TRMM has been corrected and downscaled for Ecuador from its native $27 \mathrm{~km}$ resolution to $5 \mathrm{~km}$ (Ulloa et al., 2017). This corrected product is a unique opportunity for studying spatial patterns of climate teleconnections in Ecuador.

The objective of this study is to characterize the spatial association of climate teleconnections patterns related to precipitation using an exploratory spatial data analysis approach. Specifically, by using global and local indicators of spatial association (Moran's I and LISA) to detect spatial patterns of teleconnections on TRMM satellite images.

\section{STUDY AREA AND MATERIALS}

Ecuador is one of the tropical countries located in South America (Figure 1). It receives an annual precipitation of $2300 \mathrm{~mm} /$ year, which favoured the formation of dense and every-green rainforest present in the Amazonian region (east) and in the lowlands of Pacific Coast (north-west). Additionally, Ecuador is crossed north to south by the Andes highlands, which creates a highly variable topography and micro-climates.
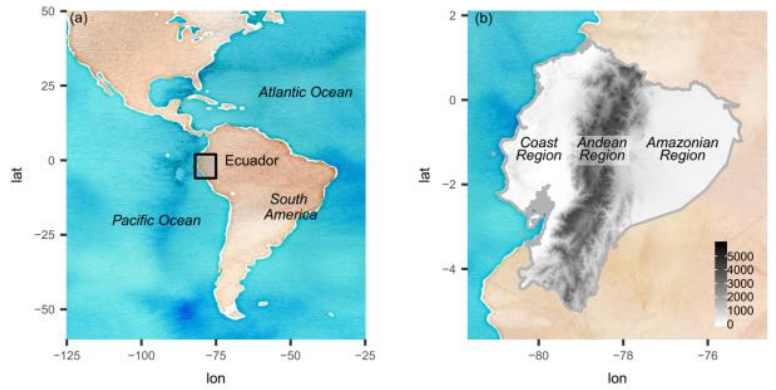

Figure 1. Study area and main climate regions of Ecuador: Coast, Highlands (Andes) and Amazon.

\subsection{Downscaled precipitation satellite data}

The main dataset consists on the monthly precipitation satellite imagery from TRMM 3b43 V7 $(27 \mathrm{~km})$, for the period of $2001-$ 2011. The downscaling method consisted in two step. First, the original available data was bilinear resampled up to $5 \mathrm{~km}$. Then, it was applied regression kriging with the in-situ stations and auxiliary variables related to cloud properties, normalized vegetation index and soil moisture (Ulloa et al., 2017). This downscaling procedure, from one side, corrected the TRMM bias, and from the other side added further variability in the data with the auxiliary environmental factors, incorporating atmospheric and land variables.

Following the terminology of R software (Ihaka \& Gentleman, 1996) and its "raster" package (Hijmans, 2017), the product is represented as a rasterbrick, where each raster layer shows the precipitation of a specific month. Additionally, each pixel in the rasterbrick contains the precipitation time series at such a location. Linear trend was removed from time series using the "Detrend" function from "SpecsVerification" library (Siegert, 2017).

\subsection{Climate indices}

The evolution and occurrence of teleconnections is monitored by using different climate indices (Hanley et al., 2003; Kiem \& Franks, 2001). Although there is no agreement on which index best captures the teleconnections (Hanley et al., 2003), the index representativeness has been linked to certain geographic areas. Following (Córdoba-Machado et al., 2016; Fierro, 2014; Liu et al., 2018), we selected the climate indices used in this study (Table 1). The temporal period was 2001 to 2011, and lineal trend was also removed. The indices were obtained from https://www.esrl.noaa.gov/psd/data/climateindices/list/, and http://www.jamstec.go.jp/frsgc/research/d1/iod/e/elnmodoki/abo ut_elnm.html.

Table 1. Climate indices for teleconnection exploration.

\begin{tabular}{|c|c|}
\hline Index & Description \\
\hline \multicolumn{2}{|c|}{ Pacific Ocean } \\
\hline soi & $\begin{array}{l}\text { Southern Oscillation Index is based on the } \\
\text { atmospheric pressure difference between Tahiti } \\
\text { and Darwin }\end{array}$ \\
\hline mei & $\begin{array}{l}\text { Multivariate ENSO Index combines oceanic and } \\
\text { atmospheric variables. }\end{array}$ \\
\hline modoki & $\begin{array}{l}\text { Niño Modoki is a coupled ocean-atmosphere } \\
\text { phenomenon in the tropical Pacific, associated } \\
\text { with strong anomalous warming in the central } \\
\text { tropical Pacific and cooling in the eastern and } \\
\text { western tropical Pacific. }\end{array}$ \\
\hline niño1+2 & $\begin{array}{l}\text { It measures the SST in the region } 0-10 \mathrm{~S}, 90 \mathrm{~W}- \\
80 \mathrm{~W} \text { eastern Pacific (close to Ecuador and Peru). }\end{array}$ \\
\hline niño3 & $\begin{array}{l}\text { It measures the SST in the region } 5 \mathrm{~N}-5 \mathrm{~S}, 150 \mathrm{~W}- \\
90 \mathrm{~W} \text { in Pacific ocean. }\end{array}$ \\
\hline niño3.4 & $\begin{array}{l}\text { It measures the SST in the region } 5 \mathrm{~N}-5 \mathrm{~S}, 170 \mathrm{~W}- \\
120 \mathrm{~W} \text { in Pacific ocean. }\end{array}$ \\
\hline niño4 & $\begin{array}{l}\text { It measures the SST in the region } 5 \mathrm{~N}-5 \mathrm{~S}, 160 \mathrm{E}- \\
150 \mathrm{~W} \text { in Pacific ocean. }\end{array}$ \\
\hline oni & $\begin{array}{l}\text { Oceanic Niño Index located in 5N-5S, 170W- } \\
\text { 120W Pacific Ocean (same region as Niño3.4). }\end{array}$ \\
\hline tni & $\begin{array}{l}\text { Trans Niño Index is the difference in normalized } \\
\text { SST anomalies between Niño1+2 and Niño4 } \\
\text { regions. }\end{array}$ \\
\hline$n$ & fic Index is the areal-weighted sea le \\
\hline
\end{tabular}


pressure over the region $30 \mathrm{~N}-65 \mathrm{~N}, 160 \mathrm{E}-140 \mathrm{~W}$.

pna

Pacific North American teleconnection index is one of the most prominent modes of low

frequency variability in the Northern Hemisphere extra-tropics.

\begin{tabular}{|c|c|}
\hline \multicolumn{2}{|c|}{ Atlantic Ocean } \\
\hline ammsst & $\begin{array}{l}\text { Atlantic Meridional Mode describes SST in the } \\
\text { meridional variability in tropical Atlantic ocean. }\end{array}$ \\
\hline amon & $\begin{array}{l}\text { The Atlantic Multi-decadal Oscillation is a } \\
\text { coherent mode of natural variability in the North } \\
\text { Atlantic ocean (estimated period of } 60-80 \text { years). }\end{array}$ \\
\hline Car_erst & $\begin{array}{l}\text { Caribbean SST Index are SST anomalies } \\
\text { averaged over the Caribbean Sea. }\end{array}$ \\
\hline tsa & $\begin{array}{l}\text { Tropical Southern Atlantic Index is an anomaly of } \\
\text { monthly average SST, Eq-20S and 10E-30W. }\end{array}$ \\
\hline
\end{tabular}

\section{METHODS}

First, the teleconnections were detected based on high correlation values and then an exploratory spatial data analysis (ESDA) was performed. ESDA provides a set of indicators to explore spatial autocorrelation, and their results are useful to build hypothesis about the spatial behaviour of the study variable. In our case, global and local indicators of spatial association were computed based on spatial weights matrix.

\subsection{Pixel-wise correlation}

Due the lack of normality, the correlation between the precipitation time series at each pixel of the rasterbrick with each climate index was computed using Spearman's $\rho$. The correlation was performed at $t_{0}$, i.e. lagged correlation was not performed. Values of $\rho$ were obtained for each pixel and climate index, and thus correlation maps were plotted. Correlation values larger than 0.3 or smaller than -0.3 were identified as teleconnections. Since the focus is on the spatial patterns of the correlation strength, maps with the absolute value of $\rho$ for each index were obtained. Thus it was represented the degree of relation (strength) regardless the direction of such relation.

\subsection{Spatial autocorrelation}

Spatial autocorrelation measures the degree of association that a variable develops through the geographical space. It quantifies how much the value of a variable at one location depends on the values of the same variable measured at a specific geographic distance from that location. The essence of spatial autocorrelation is to analyse the variability of a phenomenon through the geographical space to determine spatial patterns and describe its behaviour, that is, how much local elements can be affected by their neighbours (Siabato \& Guzmán-Manrique, 2019). It is an exploratory spatial statistical approach that allows to detect how stable (heterogeneity-dependence and statistically significant) is the underlying spatial phenomenon for a given pattern.

Spatial autocorrelation can be measured at the global and local levels. The global measures provide a statistic for the entire study area under the assumption of spatial stationarity, i.e. the mean and covariance do not vary over space. The local statistics allow the exploration of local patterns of spatial association, by decomposing a single global measure into the partial contribution of each individual location, and to detect the locations that are major contributors to the global autocorrelation (Naimi et al.,
2019). We used Moran's I to assess the spatial autocorrelation at the global level (Anselin, 1993; Moran, 1948) and LISA to assess it at the local (Anselin, 1995). Although many other global and local statistics exist (Bivand \& Wong, 2018), it was selected Moran's I and LISA because they have been widely implemented.

\subsection{Spatial weights matrix}

The spatial relationship between a location and its neighbours is represented using a matrix that stores the spatial structure of the weighted influence of a neighbourhood (de Smith et al., 2018). It is assumed that the influence is only dependent on the distance, thus it can be represented by an inverse distance weighted function. In order to include only the neighbours that actually have some influence, and to reduce the size of the matrix, a cut off distance is usually necessary. In our case, we defined a neighbourhood based on cut off distance of $5 \mathrm{~km}$ (Euclidian distance). Additionally, given that the border pixels (Ecuadorian country limits) had a reduced number of neighbours, and to avoid invalidating of the statistical approach when none or limited observations are present in the neighbourhood, a row standardization of the spatial relationships matrix was performed (de Smith et al., 2018; Orellana \& Wachowicz, 2011).

\subsection{Moran's I}

Moran's I is a cross-product statistic between a variable and its spatial lag (at a defined neighborhood), with the variable expressed in deviations from its mean. At a location $i$, it is expressed as $Z_{i}=x_{i}-\bar{x}$ where $\bar{x}$ is the mean of variable $x$ (Anselin, 1993; Moran, 1948). Moran's I statistic is then:

$$
I=\frac{\sum_{i} \sum_{j} w_{i j} z_{j} / S_{o}}{\sum_{i} z_{i}^{2} / n}
$$

with $w_{i j}$ as the elements of the spatial weights matrix, $S_{o}=\sum_{i} \sum_{j} w_{i j}$ as the sum of all the weights, and $n$ as the number of observations.

Moran's I returns values between -1 and +1 . If I $<0$, then spatial autocorrelation is negative showing a disperse pattern, i.e. association of dissimilar values. If $\mathrm{I}>0$, then spatial autocorrelation is positive with a homogeneous or clustered pattern, i.e. association of similar values. If $\mathrm{I}=0$, there is no evidence of spatial autocorrelation or the phenomenon shows a random spatial distribution.

In order to determine the global spatial autocorrelation at different distance ranges, a correlogram was used. It allows to compare the global spatial autocorrelation at short and large ranges (Naimi et al., 2019). In order words, how spatial autocorrelation varies in relation to distance. The statistical significance of the global spatial association was tested using a randomization approach (i.e., each value is equally likely to occur at any location) for ranges of 5, 15, 35 and $100 \mathrm{~km}$. The null hypothesis of spatial randomness was tested with a two sided approach and a significance level of 0.05 .

\subsection{LISA}

A Local Indicator of Spatial Association (LISA) is any statistics that satisfies (Anselin, 1995): (i) the LISA for each observation gives an indication of the extent of significant spatial clustering of similar values around that observation; and (ii) the sum of 
LISAs for all observations is proportional to a global indicator of spatial association. Therefore, a LISA is useful to measure the contribution of each observation to the global association.

LISA uses this last property to evaluate the spatial association by calculating local Moran's I and then to evaluate the statistical significance of each unit. Three calculation steps were performed (Orellana \& Wachowicz, 2011): 1) The LISA value and its respective Z-score were computed for each pixel (with the respective defined neighbours). High positive values indicated that an observation was surrounded by observations with similar values, and high negative values indicated that an observation was surrounded by very different values. 2) A hypothesis testing was applied based on a null hypothesis of spatial randomness (i.e. no spatial association of nearby pixels) at a 0.05 significant level (two sided); then, pixels with significant spatial association were selected for the next step. 3) Spatial clusters and outliers were detected based on a scatterplot of the standardized values of the LISA and of the original variable. Four quadrants can be identified based on the means or the $0 \mathrm{z}$-score, in order to classify spatial clusters or spatial outliers. If the variable and the LISA z-scores > 0, a High-High or "hotspots" are detected. These are homogeneous regions with high correlation values also with high neighbourhood values. If the variable and the LISA zscore $<0$, the Low-Low or "coldspots" are detected. These are homogeneous regions with low correlation values also with low neighbourhood values. The remaining quadrants represent spatial outliers of dispersed values. Because our analysis is performed on continuous raster data, the three calculation steps can be plotted in maps.

\section{IMPLEMENTATION}

Implementation was done in $\mathrm{R}$ using several libraries. The rasterbrick satellite images of precipitation were handled with the library raster (Hijmans, 2017); the correlograms were calculated with elsa (Naimi et al., 2019); and Moran's I and LISA, including the hypothesis testing were performed with spdep (Bivand \& Wong, 2018).

\section{RESULTS AND DISCUSSION}

\subsection{Correlation maps}

Correlation maps showed positive correlations in blue, and negative in red (Figure 2). A positive correlation means that when the value of a climate index increases, the precipitation also increases; while a negative correlation means that when the index increases, the precipitation is expected to decrease. Whether such correlations were larger than 0.3 or smaller than -0.3 (i.e. moderate to high correlations), they depicted the presence of climate teleconnections. The larger positive detected teleconnection was for niño1+2, followed by niño3 also with positive correlation, and niño4 with negative and positive correlations. Some indices such as niño1+2, niño3, ammon, and Car_errst showed the same direction for the relation in the whole study area (i.e. positive or negative), while others showed regions with positive and negative relations.

\subsection{Global spatial association}

As it is expected for continuous raster data, that have smooth and gradual value transitions, the Moran's I value showed high positive spatial association (larger than 0.5$)$ from short $(5 \mathrm{~km})$ to medium ranges $(100 \mathrm{~km})$. Moran'I at $5,35,50$ and $100 \mathrm{~km}$ were proved to be statistically significant with a p-value smaller than 0.5 .

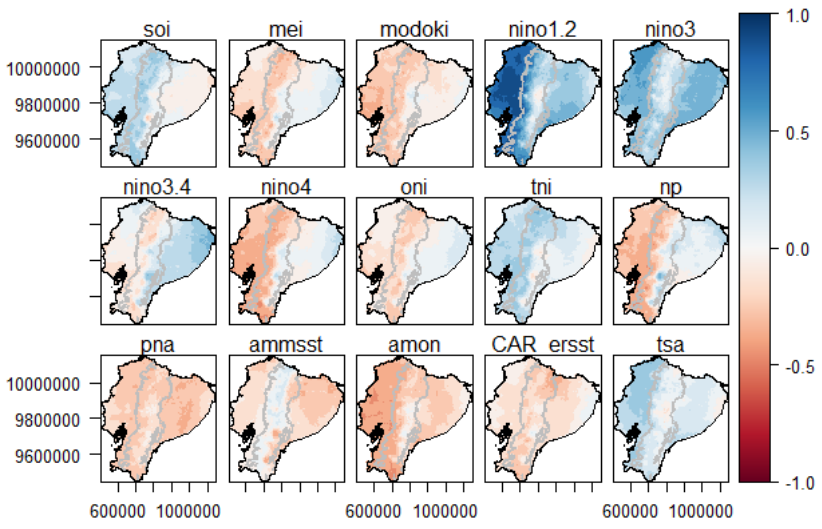

Figure 2. Correlation maps of climate teleconnection from Pacific and Atlantic climate indices.

From the correlograms (not showed here for the sake of space), it was observed that the spatial association decreased while the neighbourhood increased. The teleconnections from the Pacific Ocean, such as soi, niño12, niño34, niño4, tni and np, reached the 0.5 Moran's I value around the $100 \mathrm{~km}$ distance; mei, niño3 and oni did it at a shorter distance than $100 \mathrm{~km}$ (around 50 to $60 \mathrm{~km})$; while modoki at larger distance than $100 \mathrm{~km}$. The teleconnections from the Atlantic showed similar pattern than that from the Pacific. Ammst, amon and tsa reached the 0.5 Moran's I value around the $100 \mathrm{~km}$ distance; while Car_errst and pna at shorter distance than $100 \mathrm{~km}$ (around $50 \mathrm{~km}$ ). This agree with the observed spatial distribution of correlation maps, in the sense that teleconnections with spatial associations at larger ranges also showed homogenous and extensive influences in the correlation maps. An exception for this pattern was observed for niño3, that although with extensive pattern it showed a medium range spatial autocorrelation.

\subsection{Local spatial association}

LISA showed local spatial association by combining two types of information: clustered areas and significant local spatial association. On the one side, the clusters or homogeneous regions had high correlation values also with high neighbour values $(\mathrm{HH}$, High-High cluster, represented in dark grey colour, Figure 3), and low correlation values also with low neighbour values (LL, Low-Low cluster, represented light grey colour). On the other side, only locations with significant spatial autocorrelation were shown. In such locations, it was rejected the randomness hypothesis or the lack of spatial association (i.e. dark and light grey areas were significant locations). Thus, $\mathrm{HH}$ and LL clusters represented significant spatial association of the teleconnections.

Additionally, the significant clustered maps were overlapped with the moderate to high correlation areas (larger than 0.3 or smaller than -0.3). They are shown in figure 3 with blue the positive correlations and in red the negative correlations.

It was identified two patterns: homogeneous and disperse (Table 2). The homogenous pattern is characterized by the homogeneous and extensive teleconnections (correlation maps), also overlapped with homogeneous and extensive spatial association patterns (significant LISA maps). These patterns were mainly localized in the Coast and Amazonian regions (niño1+2, niño3, niño4, amon and tsa). In general, the $\mathrm{HH}$ 
clusters had a more reduced (smaller) extension than the teleconnections influences. This means that although the correlation of a climate index with precipitation could be high, there is also a spatial randomness process (local climate drivers) such as topography, mountain orientation, local wind and microclimates, that might be playing a role to explain such high correlation. For instance, in the case of niño1+2, there were not significant spatial association in the western Andes slope, showing that in the highlands a spatial randomness process takes place. In the Amazon, niño1+2 and niño3 had moderate positive correlation, however such patterns were not supported by significant spatial association. The existence of a $\mathrm{HH}$ clustered with lack of significant spatial association does not contradict the influence of the teleconnection itself. Instead it pointed out the need to explore local climate drivers that might be interacting with the teleconnection. In the case of niño34, the HH cluster had a larger extension than the teleconnections influence, which shows that although with low correlation values, the spatial association is still large and significant.

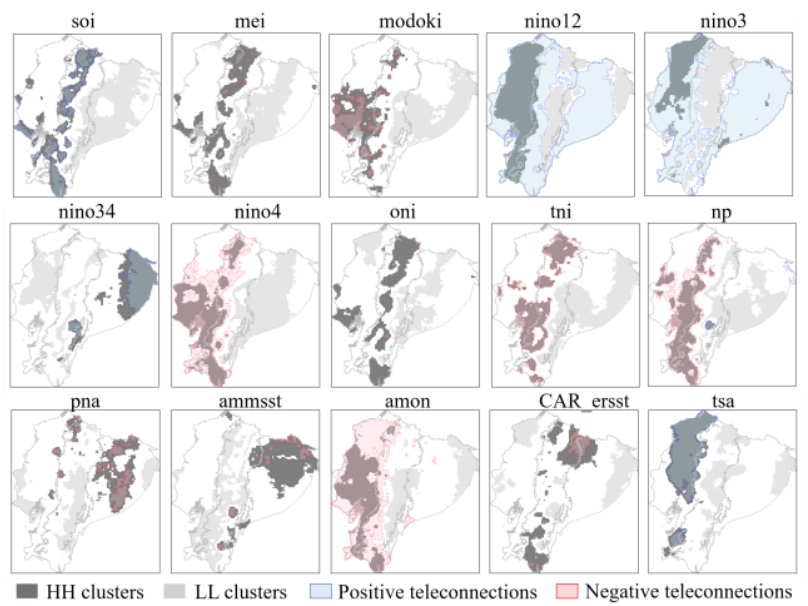

Figure 3. LISA clustered maps with significant spatial association. Dark gray areas are HH clusters, light gray areas are LL clusters, and white areas means spatial randomness. Blue polygons are moderate to high positive correlation, and the red ones are moderate to high negative correlation.

Table 2. Summary of detected patterns of spatial association.

\begin{tabular}{llll}
\hline Pattern & Coast & Highlands & Amazon \\
\hline Homogeneous & $\begin{array}{l}\text { Pacific } \\
\text { niño1+2 } \\
\text { niño3, niño4 }\end{array}$ & & $\begin{array}{l}\text { Pacific } \\
\text { niño34 } \\
\text { pna }\end{array}$ \\
& $\begin{array}{l}\text { Atlantic } \\
\text { amon, tsa }\end{array}$ & & \\
Disperse & Pacific & Pacific & Atlantic \\
& $\begin{array}{l}\text { modoki } \\
\text { tni } \\
\text { np }\end{array}$ & $\begin{array}{l}\text { modoki } \\
\text { niño4, oni } \\
\text { tni, np, pna }\end{array}$ & car_ersst \\
& & & \\
\hline
\end{tabular}

The disperse pattern is characterized by disperse teleconnections (correlation maps), also overlapped with disperse spatial association patterns (significant LISA maps). These patterns were mainly localized in the Highlands (soi, mei, modoki, niño4, oni, tni, np, pna), central-south part of the Coast (modoki, tni, $\mathrm{np}$ ), and centre of Amazonian region (ammsst, car_ersst). In these cases, the spatial association clusters played an important role by confirming the disperse teleconnection patterns and showing that the presence of an underlying local process that might help explaining such teleconnections. For instance, in the highlands region could be the altitude and the mountain orientation that manage to capture moisture. This pointed out the need to explore the interaction of precipitation with local drivers and further teleconnections in order to identify the physical process that might explain such patterns.

\section{CONCLUSIONS}

This study explored spatial autocorrelation of climate teleconnection in the tropical country of Ecuador. Moran' I global and LISA local indicators were used. The results showed that although Moran's I depicted high positive spatial association in all the cases, LISA also allowed to identify two types of teleconnections patterns: homogenous and disperse. The homogenous patterns were localized in the Coast and Amazonian region. Meanwhile the disperse patterns were localized in the three regions of the country, with a major presence in the Highlands.

In the Coast, homogeneous teleconnections were detected with Pacific indices niño 1+2, niño 3, niño 4, and Atlantic indices amon and tsa. Disperse relations in the Coast were modoki, tni and $\mathrm{np}$, highlighting the influence of lower than annual frequency oscillations and suggesting that precipitation in the Coast has inter-annual and longer influences. For the Amazon homogeneous teleconnections with Pacific indices were found with niño 3.4 and tna. Disperse teleconnections were detected with Atlantic Ocean indices such as ammsst and Caribean car_ersst. Only dispense teleconnections were found in the Andes probably due to more local precipitation occurrence in this complex terrain.

Despite the important findings already shown, the main limitation of this study is the lack of seasonal analysis due to the high spatio-temporal features of the climate system. Thus further studies may go on this direction. In addition, the used data was corresponding a 10 years' period, up to 2011. Therefore, it is needed to extend and update the temporal period in order to capture decadal variations and trends in the teleconnections.

Moran's I and LISA are exploratory spatial methods, useful for hypothesis building. Thus this study focalized out attention in two directions for further research. First, in those geographic areas that, even if they had moderate to high teleconnection influences, there also were random spatial patterns (i.e. without significant spatial association). Second, in those areas that both teleconnections and significant spatial association were similar, but dispersed. This study pointed out the need to identify the local underlying features that restricts (smaller spatial association patterns) or reaffirms (disperse patterns) the teleconnection patterns. In this regards, our hypothesis is that the presence of local climate drivers such as topography, mountain orientation, local wind and micro-climates, might be playing a role to explain such patterns.

\section{ACKNOWLEDGEMENTS}

This study has been financed by the Corporación Ecuatoriana para el Desarrollo de la Investigación y la Academia (CEDIA) through the project CEPRA XII "Spatial representation of climatic teleconnections in the precipitation of Ecuador".

\section{REFERENCES}

Ångström, A. (1935). Teleconnections of climatic changes in 
present time. Geografiska Annaler, 17(3-4), 242-258. https://doi.org/DOI: 10.2307/519964

Anselin, L. (1993). The Moran scatterplot as an ESDA tool to assess local instability in spatial association. Regional Research Institute, West Virginia University Morgantown, WV.

Anselin, L. (1995). Local indicators of spatial associationLISA. Geographical Analysis, 27(2), 93-115. https://doi.org/https://doi.org/10.1111/j.1538-

4632.1995.tb00338.x

Ballari, D., Castro, E., \& Campozano, L. (2016). Validation of Satellite Precipitation (trmm 3B43) in Ecuadorian Coastal Plains, Andean Highlands and Amazonian Rainforest. ISPRS International Archives of the Photogrammetry, Remote Sensing and Spatial Information Sciences, 305-311.

Bivand, R. S., \& Wong, D. W. S. (2018). Comparing implementations of global and local indicators of spatial association. TEST. https://doi.org/10.1007/s11749-018-0599-х

Carleton, A. M. (2003). Atmospheric teleconnections involving the Southern Ocean. Journal of Geophysical Research: Oceans, 108(C4). https://doi.org/https://doi.org/10.1029/2000JC000379

Córdoba-Machado, S., Palomino-Lemus, R., Gámiz-Fortis, S. R., Castro-Diez, Y., \& Esteban-Parra, M. J. (2016). Seasonal streamflow prediction in Colombia using atmospheric and oceanic patterns. Journal of Hydrology, 538, 1-12. https://doi.org/https://doi.org/10.1016/j.jhydrol.2016.04.003

de Smith, M. J., Goodchild, M. F., \& Longley, P. A. (2018). Geospatial Analysis. A Comprehensive Guide to Principles Techniques and Software Tools (6th ed.). Retrieved from www.spatialanalysisonline.com

Diaz, H. F., Hoerling, M. P., \& Eischeid, J. K. (2001). ENSO variability, teleconnections and climate change. International Journal of Climatology, 21(15), 1845-1862. https://doi.org/https://doi.org/10.1002/joc.631

Fierro, A. O. (2014). Relationships between California rainfall variability and large-scale climate drivers. International Journal of Climatology, 34(13), 3626-3640. https://doi.org/https://doi.org/10.1002/joc.4112

Hanley, D. E., Bourassa, M. A., O’Brien, J. J., Smith, S. R., \& Spade, E. R. (2003). A quantitative evaluation of ENSO indices. Journal of Climate, 16(8), 1249-1258. https://doi.org/https://doi.org/10.1175/15200442(2003)16<1249:AQEOEI>2.0.CO;2

Hijmans, R. J. (2017). raster: Geographic Data Analysis and Modeling. $\mathrm{R}$ package version 2.6-7. Retrieved from https://cran.r-project.org/package=raster

Huffman, G. J., Bolvin, D. T., Nelkin, E. J., Wolff, D. B., Adler, R. F., Gu, G., ... Stocker, E. F. (2007). The TRMM multisatellite precipitation analysis (TMPA): Quasi-global, multiyear, combined-sensor precipitation estimates at fine scales. Journal of Hydrometeorology, 8(1), 38-55.

Ihaka, R., \& Gentleman, R. (1996). R: a language for data analysis and graphics. Journal of Computational and Graphical Statistics, 5(3), 299-314.

Kiem, A. S., \& Franks, S. W. (2001). On the identification of ENSO-induced rainfall and runoff variability: a comparison of methods and indices. Hydrological Sciences Journal, 46(5),
715-727.

https://doi.org/https://doi.org/10.1080/02626660109492866

Liu, Y.-C., Di, P., Chen, S.-H., \& DaMassa, J. (2018). Relationships of Rainy Season Precipitation and Temperature to Climate Indices in California: Long-Term Variability and Extreme Events. Journal of Climate, 31(5), 1921-1942. https://doi.org/https://doi.org/10.1175/JCLI-D-17-0376.1

Liu, Z., \& Alexander, M. (2007). Atmospheric bridge, oceanic tunnel, and global climatic teleconnections. Reviews of Geophysics, https://doi.org/https://doi.org/10.1029/2005RG000172

Maggioni, V., Meyers, P. C., \& Robinson, M. D. (2016). A review of merged high-resolution satellite precipitation product accuracy during the Tropical Rainfall Measuring Mission (TRMM) Era. Journal of Hydrometeorology, 17(4), 11011117. https://doi.org/https://doi.org/10.1175/JHM-D-15-0190.1

Moran, P. A. P. (1948). The interpretation of statistical maps. Journal of the Royal Statistical Society. Series B (Methodological), 10(2), 243-251. Retrieved from https://www.jstor.org/stable/2983777

Naimi, B., Hamm, N. A. S., Groen, T. A., Skidmore, A. K., Toxopeus, A. G., \& Alibakhshi, S. (2019). ELSA: Entropybased local indicator of spatial association. Spatial Statistics, 29, 66-88.

Ochoa, A., Pineda, L., Crespo, P., \& Willems, P. (2014). Evaluation of TRMM 3B42 precipitation estimates and WRF retrospective precipitation simulation over the Pacific-Andean region of Ecuador and Peru. Hydrology and Earth System Sciences, 18(8), 3179-3193. https://doi.org/10.5194/hess-183179-2014

Orellana, D., \& Wachowicz, M. (2011). Exploring Patterns of Movement Suspension in Pedestrian Mobility. 行人移动停靠模式的探索性分析. Geographical Analysis, 43(3), 241-260. https://doi.org/10.1111/j.15384632.2011.00818.x

Salio, P., Hobouchian, M. P., Skabar, Y. G., \& Vila, D. (2015). Evaluation of high-resolution satellite precipitation estimates over southern South America using a dense rain gauge network. Atmospheric Research, 163, 146-161. https://doi.org/https://doi.org/10.1016/j.atmosres.2014.11.017

Siabato, W., \& Guzmán-Manrique, J. (2019). La autocorrelación espacial y el desarrollo de la geografía cuantitativa. Cuadernos de Geografía: Revista Colombiana de Geografía, 28(1), 1-22. https://doi.org/https://doi.org/10.15446/rcdg.v28n1.76919

Siegert, S. (2017). SpecsVerification: Forecast Verification Routines for Ensemble Forecasts of Weather and Climate. $\mathrm{R}$ package version 0.5-2. Retrieved from https://cran.rproject.org/package=SpecsVerification

Ulloa, J., Ballari, D., Campozano, L., \& Samaniego, E. (2017). Two-Step Downscaling of Trmm 3b43 V7 Precipitation in Contrasting Climatic Regions With Sparse Monitoring: The Case of Ecuador in Tropical South America. Remote Sensing, 9(7), 758. https://doi.org/https://doi.org/10.3390/rs9070758 